\title{
Yin Yang Haplotypes Revisited - Long, Disparate Haplotypes Observed in European Populations in Regions of Increased Homozygosity
}

\author{
David Curtis Anna E. Vine \\ Centre for Psychiatry, Queen Mary's School of Medicine and Dentistry, London, UK
}

\section{Key Words}

Homozygosity · Extended haplotypes $\cdot$ Yin yang

haplotypes

\begin{abstract}
Objectives: Yin yang haplotypes differ at every SNP. A previous study provided striking examples of these haplotypes, but claimed that their distribution across the genome could be attributed to chance. When we studied regions of homozygosity ( $\mathrm{ROH}$ ) we found haplotypes that tended to differ at several SNPs simultaneously but did not subject this to formal testing. Here, we formally assess whether haplotypes from these regions provide evidence for the yin yang effect. Method: We identified 20 regions where $\mathrm{ROH}$ s are common in a sample of European subjects and studied the most frequent haplotypes of SNPs with high minor allele frequency. We calculated the average 'disparity' between all haplotype pairs using a 'disparity score' calculated as $2^{d}$, where $d$ is the number of SNPs at which a pair of haplotypes differ. We also studied these SNPs in HapMap samples. Results: Overall, there was highly significant evidence for excess haplotype disparity. Three of the HapMap populations with European ancestry also had statistically significant haplotype disparity scores. Conclusion: Locations where ROHs are frequent harbour long common haplotypes showing surprising disparity.
\end{abstract}

We believe these haplotypes must represent ancient founder effects and could be valuable for elucidating features of a population's history.

Copyright $\odot 2010$ S. Karger AG, Basel

\section{Introduction}

Previous reports have drawn attention to the phenomenon of 'yin yang' haplotypes [1,2]. A 'yin yang haplotype pair' is a pair of haplotypes where every SNP has a different allele in each of the haplotypes. Such an observation is remarkable because it is exactly the opposite of what one would expect to observe if haplotypes were generated by a process of sequential mutation. Taking a naïve view of sequential mutation, one would have to conceive of all loci as being originally monomorphic. At some point, a mutation would occur to produce a SNP with two allelic forms. Later in the population's history, a subsequent mutation would occur. Probably it would occur on the background of the original haplotype, but it might occur in a chromosome bearing the previous mutation. In any event, one would expect eventually to build up a set of haplotypes which could be linked with each other through changes at single SNPs. The situation would be complicated by recombination, and some haplotypes might be 
lost through genetic drift. However, what one would not, intuitively, expect to happen would be for pairs of haplotypes which differed simultaneously at all SNPs to be produced. Table 1 illustrates examples of haplotype sets one might expect to emerge from a process of sequential mutation.

A previous study investigated this phenomenon and provided striking examples of haplotypes of up to 24 SNPs which demonstrated the yin yang effect [1]. SNPs from a variety of genomic regions were selected as having minor allele frequency (MAF) ranging from 0.01 to 0.2 . A yin yang pair of haplotypes was formally defined as consisting of two common (frequency $>0.03$ ) haplotypes of at least 5 consecutive SNPs. Yin yang regions, in which such pairs could be identified, covered $75-85 \%$ of the genome when SNPs with MAF $>0.1$ were considered. This phenomenon was observed in four different human populations and in Drosophila. In the human populations the average number of SNPs forming each haplotype pair varied between 8 and 10, covering regions up to $54 \mathrm{~kb}$ in size.

As the authors described, they were originally surprised at the high prevalence of yin yang regions and they pointed out that the suggested causes of highly divergent haplotypes included population admixture, gene conversion and chromosomal inversions. However, they went on to carry out coalescent simulation and found that their results were, perhaps counterintuitively, compatible with a neutral evolutionary model incorporating mutation and recombination.

We have reported on this phenomenon beginning with a somewhat different approach. We studied regions of homozygosity (ROHs), in which many consecutive SNPs were homozygous [2]. We defined a $\mathrm{ROH}$ to be a minimum of 10 homozygous SNPs extending over a minimum of $1 \mathrm{Mb}$. We investigated the distribution and nature of these regions in a sample of 1,411 subjects. We found an average of 35.9 such regions occurring per subject and found the regions to contain an average of 73 consecutive homozygous SNPs. We went on to study locations in which an $\mathrm{ROH}$ would be found in a large proportion of subjects, and we studied the haplotypes formed from the 11 SNPs at the centre of each of these regions. We reported that such haplotypes tended to differ simultaneously at several different SNPs, supporting the yin yang phenomenon, and that this appeared to occur more often than would be expected by chance, but we did not carry out a formal statistical evaluation of this observation.

A number of studies have shown that extended $\mathrm{ROHs}$ are surprisingly common in outbred populations [2-4].
Table 1. Example sets of haplotypes expected under models of sequential mutation and without recombination

Set of haplotypes which would be observed if each mutation occurred on the background of the original haplotype, 11111111

$\begin{array}{lllllllll}1 & 1 & 1 & 1 & 1 & 1 & 1 & 1 & 1 \\ 1 & 1 & 1 & 1 & 1 & 1 & 1 & 1 & 2 \\ 1 & 1 & 1 & 1 & 1 & 1 & 1 & 2 & 1 \\ 1 & 1 & 1 & 1 & 1 & 1 & 2 & 1 & 1 \\ 1 & 1 & 1 & 1 & 1 & 2 & 1 & 1 & 1 \\ 1 & 1 & 1 & 1 & 2 & 1 & 1 & 1 & 1 \\ 1 & 1 & 1 & 2 & 1 & 1 & 1 & 1 & 1 \\ 1 & 1 & 2 & 1 & 1 & 1 & 1 & 1 & 1 \\ 1 & 2 & 1 & 1 & 1 & 1 & 1 & 1 & 1 \\ 2 & 1 & 1 & 1 & 1 & 1 & 1 & 1 & 1\end{array}$

Set of haplotypes which might be observed if some mutations occurred in a haplotype already containing one or more earlier mutations

$\begin{array}{lllllllll}1 & 1 & 1 & 1 & 1 & 1 & 1 & 1 & 1 \\ 1 & 1 & 1 & 1 & 1 & 1 & 1 & 1 & 2 \\ 1 & 1 & 1 & 1 & 1 & 1 & 1 & 2 & 2 \\ 1 & 1 & 1 & 1 & 1 & 1 & 2 & 1 & 1 \\ 1 & 1 & 1 & 1 & 1 & 2 & 1 & 1 & 1 \\ 1 & 1 & 1 & 1 & 2 & 1 & 1 & 1 & 2 \\ 1 & 1 & 1 & 2 & 2 & 1 & 1 & 1 & 2 \\ 1 & 1 & 2 & 1 & 1 & 1 & 1 & 1 & 1 \\ 1 & 2 & 1 & 1 & 1 & 1 & 1 & 2 & 2 \\ 2 & 1 & 1 & 1 & 1 & 1 & 1 & 1 & 1\end{array}$

One possible explanation for observing such a region would be a deletion causing hemizygosity. However, this does not seem to be the usual cause. A study using microsatellite markers concluded that such areas were due to autozygosity, that is, subjects receive a copy of the same ancestral haplotype from each parent [5]. This conclusion was supported by a subsequent study using finely spaced SNPs which found no excess of apparent transmission errors in the ROHs studied, as would be expected if they were due to deletions [6]. Given that ROHs result from autozygosity, when an $\mathrm{ROH}$ is observed this implies that there is an extended haplotype present at such a high frequency that two copies of it happen to be inherited by the same subject. Taking this view, locations at which $\mathrm{ROHs}$ are common mark areas of the genome in which certain extended haplotypes have high frequency. For this to occur, recombination must be unusual because otherwise the extended haplotypes would be rapidly degraded. We observed that $\mathrm{ROHs}$ tended to occur at centromeres, where recombination rates are low, as well as at other locations [2]. It is not clear whether other conditions apart from low recombination are required to maintain the 
high frequency extended haplotypes which produce ROHs.

A subsequent study implementing an approach termed whole-genome homozygosity association (WGHA) used a somewhat different method for defining common ROHs and then looked to see if they differed in frequency between cases and controls [7]. This study found that $\mathrm{ROH}$ s were more common in cases of schizophrenia than in controls. We applied this method to a sample of bipolar cases and found no difference in frequency of ROHs [8].

In the current study, we use the same method to identify locations at which $\mathrm{ROH}$ are common as described for the WGHA approach [7], and we then go on to study haplotypes from these regions to see if they provide evidence for a yin yang effect. We emphasise that this approach is quite different from the method of defining yin yang regions used previously [1]. Rather than investigating the occurrence of such regions throughout the genome, we wished to focus on regions where long haplotypes had survived intact in order to study whether such extended haplotypes provided evidence for a yin yang effect.

\section{Method}

We used the control data from the 1958 British Birth Cohort (58C) which we obtained online from the Wellcome Trust Case Control Consortium after their approval was granted [9]. The genotypes had been obtained using the Affymetrix $500 \mathrm{~K}$ chip and were available for 1,504 subjects. We used the genotypes called by the Chiamo algorithm and excluded those having either a studywise missing data proportion of $>0.05$ or a studywise MAF of $<0.05$ along with a studywise missing data proportion of $>0.01$. After these exclusions were applied, we investigated genotypes for 474,008 markers in 1,480 subjects.

In order to define a region where $\mathrm{ROH}$ were common, we used the same method as described for the WGHA approach [7]. An $\mathrm{ROH}$ in an individual subject was defined using the criterion that 100 or more consecutive SNPs on a single chromosome did not receive a heterozygous call. Such SNPs would have needed to survive the quality control process noted above and hence would have had to have a MAF of at least 0.05. Common ROHs were defined as consisting of runs of at least 100 consecutive SNPs which all appeared within an $\mathrm{ROH}$ in a particular number of subjects, which was set arbitrarily to identify the desired number of common ROHS. Once a common ROH was defined it was called as 'present' or 'absent' for each subject depending on whether a subject had an $\mathrm{ROH}$ which overlapped to any extent with this common $\mathrm{ROH}$.

We then set a threshold for the number of subjects having an $\mathrm{ROH}$ to be such as to identify 20 common ROHs, which would then consist of the 20 locations at which the largest number of subjects had an $\mathrm{ROH}$. Once we had done this, we expanded the boundaries of the regions of interest to include all the individual
ROHs in these subjects, rather than limiting it to the area of overlap between the individual ROHs.

We visually inspected the haplotypes which were homozygous in these subjects. We observed that they appeared to differ from each other at several alleles simultaneously, supporting a yin yang effect. In order to test this formally we went on to study the haplotypes formed from SNPs with high MAF in these regions. From each region of interest, we selected the 9 SNPs with highest MAF and then estimated haplotype frequencies using the GENECOUNTING program [10] which estimates maximum likelihood haplotype frequencies from unphased multilocus genotypes. We chose a figure of 9 for the number of SNPs to be used in order to generate a reasonable number of different haplotypes while still having a problem which was computationally tractable and with the expectation that a moderate number of subjects would possess each haplotype, given the sample size used. We used the whole sample for estimating the frequencies of these 9-SNP haplotypes, rather than restricting attention only to those subjects bearing ROHs. We then studied the 10 haplotypes with highest frequency to see if they demonstrated yin yang effects.

In order to formally measure the extent to which haplotypes were different from each other, we devised a haplotype disparity score. For a pair of haplotypes, this is calculated as $2^{d}$, where $d$ is the number of SNPs with different alleles. This measure aims to give extra weight to pairs of haplotypes which are different at all or nearly all SNPs. We then calculated an average haplotype disparity score among all possible pairs of the 10 most frequent haplotypes. In order to assess whether our results differed from chance expectation, we compared each average score with the distribution one would expect from 10 haplotypes chosen at random from all possible $2^{9}=512$ haplotypes. We carried out Monte Carlo testing by using $10,000,000$ samples of 10 randomly generated different haplotypes and comparing their average disparity score with that produced by the real set of haplotypes in order to obtain an empirical $p$ value [11]. Of course, we would not expect that all possible haplotypes might be observed and indeed because of linkage disequilibrium (LD) relationships we would often expect only a small number of haplotypes to be present. Our method was designed to measure whether the haplotypes which were present differed more than would be expected if the selection was random. Of course, given the evolutionary model described above one might expect haplotypes to be far more similar to each other than a random selection would generate. Hence any observed additional disparity relative to the expectation under random selection would give even more weight to the presence of a yin yang effect.

We went on to test for LD between the regions studied. If LD were present it might suggest heterogeneity within the population. In order to investigate this, we treated each of the common haplotypes as if it was an allele of a multiallelic marker, and then we tested for LD between the haplotypes in different regions. For each region, each subject was assigned a pair of 'pseudoalleles' based on their probable haplotype make-up assessed using GENECOUNTING and the support program RUNGC [12]. Ten pseudoalleles were used to represent the 10 commonest haplotypes and an 11th to represent all the other haplotypes. We then tested for $\mathrm{LD}$ between these pseudoalleles in all pairs of regions using the program LDPAIRS [12].

In order to see if similar effects were present in other populations, we used genotypes obtained from phases 1, 2 and 3 of the 
HapMap project [13]. There were data available for 11 groups whose descriptions are as follows: African ancestry in Southwest USA (ASW) (83), Utah residents with Northern and Western European ancestry from the CEPH collection (CEU) (174), Han Chinese in Beijing, China (CHB) (86), Chinese in Metropolitan Denver, Colo. (CHD) (85), Gujarati Indians in Houston, Tex. (GIH) (88), Japanese in Tokyo, Japan (JPT) (89), Luhya in Webuye, Kenya (LWK) (90), Mexican ancestry in Los Angeles, Calif. (MEX) (77), Maasai in Kinyawa, Kenya (MKK) (171), Toscani in Italy (TSI) (88) and Yoruba in Ibadan, Nigeria (YRI) (176). Not all of these samples had been typed for all of the SNPs we had used in the $58 \mathrm{C}$ sample. For each of the 20 regions of interest, if genotypes for all 9 SNPs were available for one of the HapMap samples then we estimated the commonest 10 haplotypes and calculated the average disparity score between these haplotypes.

\section{Results}

The 20 regions of the genome where ROHs occurred most commonly are presented in table 2 . In these regions, an $\mathrm{ROH}$ was present in at least 294 subjects (19.9\% of the sample). Of the SNPs with highest MAF in these regions the first and last SNPs are shown, along with the distance between them, ranging from 574 to $14,297 \mathrm{~kb}$.

The estimated frequencies and cumulative frequencies of 9-SNP haplotypes are shown (alleles have been recoded so that allele 1 is always the commoner allele for each $\mathrm{SNP})$. It can be seen that in some regions a few haplotypes are very common. For example, in region 2 the $10 \mathrm{com}-$ monest haplotypes have a cumulative frequency of 0.99 . However, in region 12 the cumulative frequency of the 10 commonest haplotypes is only 0.17 , implying that large numbers of different haplotypes are present in the population, individually at fairly low frequency. Other regions have an intermediate status.

With regard to the yin yang effect, the results in table 2 appear quite striking. In region 1, the two haplotypes with highest frequency have different alleles at every SNP. Another pair of high-frequency haplotypes also demonstrates complete mismatch. Other regions demonstrate several examples of haplotype pairs which differ at all or nearly all SNPs. Even when the yin yang effect is not complete, the haplotypes give the strong impression of differing from each other more than would be expected under a model of sequential mutation. It appears to be the exception rather than the rule that haplotypes differ from each other by just a single SNP. Instead, it appears that groups of SNPs differ in unison to distinguish different haplotypes.

This impression is tested formally by obtaining the statistical significance of the average disparity scores compared with what might be expected if haplotypes were selected by chance. These scores are shown in table 2, and it can be seen that they vary from 46.1 to 129.6. Monte Carlo testing showed that the mean score for a set of 10 haplotypes selected at random is 37.4. For sets of haplotypes derived under a model of sequential mutation the scores are very much lower. For example, the two sets of haplotypes shown in table 1 have average disparity scores of 3.6 and 7.1. Empirical $p$ values derived from the Monte Carlo testing are shown in the final column of table 2 . These are very highly significant for the majority of regions studied, although a couple of regions do not show statistically significant evidence for unexpected disparity between haplotypes. There is no obvious relationship between the physical length of the haplotypes and the extent to which they demonstrate disparity.

The tests for LD between haplotypes in different regions were in accordance with chance expectation. Thus, there is no evidence for heterogeneity within the population studied.

Table 3 shows the average haplotype disparity scores in the HapMap populations compared with those for 58C. The 58C, CEU and TSI populations all have a lot of high, statistically significant haplotype disparity scores. These three populations all have European ancestry. By contrast, the other samples show little (ASW, CHB, CHD, GIH, JPT, MEX, MKK, YRI) or no (LWK) evidence for haplotype disparity. The average disparity scores are not higher than we would expect for randomly generated haplotypes and some are very low, comparable to those obtained for the haplotype sets derived by sequential mutation illustrated in table 1 .

\section{Discussion}

Study of the haplotypes formed by SNPs with high MAF in areas of the genome where ROHs are common reveals some interesting findings. The first thing to note is that typically only a handful of haplotypes account for most of the haplotype diversity, as demonstrated by the high cumulative frequencies for the 10 highest frequency haplotypes. For example, the 10 most frequent haplotypes in region 2 account for $99 \%$ of all haplotypes. This phenomenon occurs in spite of the fact that the haplotypes cover very large genetic distances, ranging from 574 up to $14,297 \mathrm{~kb}$. The fact that a small number of very long haplotypes are preserved in the population implies that there can be little recombination at these locations. In the absence of credible alternative explanations, the results sug- 
Table 2. The 10 most frequent haplotypes at the 20 regions where ROHs are most common in the $58 \mathrm{C}$ sample, along with the average haplotype disparity score between the 10 haplotypes and the associated empirical p value

\begin{tabular}{|c|c|c|c|c|c|c|c|c|c|c|c|}
\hline & Haplotype & $\begin{array}{l}\text { Fre- } \\
\text { quen- } \\
\text { cy }\end{array}$ & $\begin{array}{l}\text { Cumula- } \\
\text { tive fre- } \\
\text { quency }\end{array}$ & $\begin{array}{l}\text { Average } \\
\text { haplotype } \\
\text { disparity } \\
\text { score }\end{array}$ & $\mathrm{p}$ value & & Haplotype & $\begin{array}{l}\text { Fre- } \\
\text { quen- } \\
\text { cy }\end{array}$ & $\begin{array}{l}\text { Cumula- } \\
\text { tive fre- } \\
\text { quency }\end{array}$ & $\begin{array}{l}\text { Average } \\
\text { haplotype } \\
\text { disparity } \\
\text { score }\end{array}$ & $\mathrm{p}$ value \\
\hline \multirow{10}{*}{$\begin{array}{l}\text { Region } 1 \\
\text { Chr 1p343.3 } \\
\text { rs10914894 } \\
-573.61 \mathrm{~kb}- \\
\text { rs4271177 }\end{array}$} & 221121112 & 0.13 & 0.13 & \multirow[t]{10}{*}{103.3} & \multirow[t]{10}{*}{0.0000001} & \multirow{10}{*}{$\begin{array}{l}\text { Region } 6 \\
\text { Chr 4q31.21 } \\
\text { rs6857437 } \\
\text { - } 1395.47 \mathrm{~kb}- \\
\text { rs } 13102150\end{array}$} & 221111121 & 0.05 & 0.05 & \multirow[t]{10}{*}{71.2} & \multirow[t]{10}{*}{0.00008} \\
\hline & 112212221 & 0.13 & 0.26 & & & & 112222121 & 0.05 & 0.09 & & \\
\hline & 111121111 & 0.13 & 0.39 & & & & 221111112 & 0.05 & 0.14 & & \\
\hline & 112212222 & 0.13 & 0.51 & & & & 221222112 & 0.04 & 0.18 & & \\
\hline & 222212221 & 0.12 & 0.63 & & & & 112111212 & 0.04 & 0.22 & & \\
\hline & 111121112 & 0.11 & 0.74 & & & & 221111221 & 0.04 & 0.27 & & \\
\hline & 222212222 & 0.10 & 0.84 & & & & 221222221 & 0.03 & 0.30 & & \\
\hline & 221121111 & 0.10 & 0.94 & & & & 221222212 & 0.03 & 0.33 & & \\
\hline & 221111111 & 0.01 & 0.95 & & & & 112111112 & 0.03 & 0.36 & & \\
\hline & 222211111 & 0.01 & 0.96 & & & & 221222121 & 0.03 & 0.39 & & \\
\hline \multirow{10}{*}{$\begin{array}{l}\text { Region } 2 \\
\text { Chr 1q25.1 } \\
\text { rs12060864 } \\
-2223.38 \mathrm{~kb}- \\
\text { rs3795401 }\end{array}$} & 212212222 & 0.15 & 0.15 & \multirow[t]{10}{*}{109.4} & \multirow[t]{10}{*}{0.0000001} & Region 7 & 112211121 & 0.04 & 0.04 & \multirow[t]{10}{*}{64.9} & \multirow[t]{10}{*}{0.0007} \\
\hline & 121121112 & 0.14 & 0.29 & & & Chr 5q23.1 & 121121112 & 0.03 & 0.07 & & \\
\hline & 121121111 & 0.13 & 0.42 & & & rs10477535 & 112211112 & 0.03 & 0.10 & & \\
\hline & 211121111 & 0.12 & 0.54 & & & $-834.84 \mathrm{~kb}-$ & 121122212 & 0.03 & 0.12 & & \\
\hline & 122212221 & 0.12 & 0.66 & & & rs166296 & 212211112 & 0.02 & 0.15 & & \\
\hline & 212212221 & 0.11 & 0.78 & & & & 221121121 & 0.02 & 0.17 & & \\
\hline & 122212222 & 0.10 & 0.88 & & & & 212212212 & 0.02 & 0.19 & & \\
\hline & 211121112 & 0.10 & 0.98 & & & & 221111121 & 0.02 & 0.21 & & \\
\hline & 211111111 & 0.01 & 0.98 & & & & 221121112 & 0.02 & 0.23 & & \\
\hline & 121111112 & 0.01 & 0.99 & & & & 121122221 & 0.02 & 0.25 & & \\
\hline \multirow{10}{*}{$\begin{array}{l}\text { Region } 3 \\
\text { Chr 2p12 } \\
\text { rs } 4852559 \\
-3060.14 \mathrm{~kb}- \\
\text { rs9636402 }\end{array}$} & 222122112 & 0.05 & 0.05 & \multirow[t]{10}{*}{89.1} & \multirow[t]{10}{*}{0.0000002} & Region 8 & 111222222 & 0.15 & 0.15 & \multirow[t]{10}{*}{121.3} & \multirow[t]{10}{*}{0.0000001} \\
\hline & 111211222 & 0.05 & 0.09 & & & Chr 5q23.3 & 122111111 & 0.12 & 0.27 & & \\
\hline & 111222112 & 0.04 & 0.14 & & & rs12516015 & 222111111 & 0.10 & 0.37 & & \\
\hline & 222111211 & 0.04 & 0.18 & & & $-3026.24 \mathrm{~kb}-$ & 222222222 & 0.09 & 0.46 & & \\
\hline & 222122122 & 0.04 & 0.22 & & & rs4705938 & 211222222 & 0.09 & 0.55 & & \\
\hline & 222211221 & 0.04 & 0.26 & & & & 211111111 & 0.07 & 0.62 & & \\
\hline & 111111211 & 0.04 & 0.30 & & & & 111111111 & 0.07 & 0.69 & & \\
\hline & 111211211 & 0.04 & 0.34 & & & & 122222222 & 0.05 & 0.74 & & \\
\hline & 111211221 & 0.04 & 0.37 & & & & 112111111 & 0.04 & 0.78 & & \\
\hline & 111122122 & 0.04 & 0.41 & & & & 212111111 & 0.02 & 0.80 & & \\
\hline \multirow{10}{*}{$\begin{array}{l}\text { Region } 4 \\
\text { Chr 2p21.3 } \\
\text { rs11903316 } \\
-3818.23 \mathrm{~kb}- \\
\text { rs13393631 }\end{array}$} & 221222211 & 0.05 & 0.05 & \multirow[t]{10}{*}{83.5} & 0.000002 & Region 9 & 222211122 & 0.07 & 0.07 & 76.0 & 0.00002 \\
\hline & 221222222 & 0.04 & 0.08 & & & Chr 6p22.1 & 122222221 & 0.04 & 0.11 & & \\
\hline & 112111112 & 0.04 & 0.12 & & & rs2690106 & 111122212 & 0.03 & 0.15 & & \\
\hline & 112111122 & 0.03 & 0.15 & & & $-5813.97 \mathrm{~kb}-$ & 122211122 & 0.03 & 0.18 & & \\
\hline & 221111121 & 0.03 & 0.18 & & & rs9405050 & 111122221 & 0.03 & 0.20 & & \\
\hline & 221111122 & 0.03 & 0.21 & & & & 222222221 & 0.03 & 0.23 & & \\
\hline & 112222221 & 0.02 & 0.23 & & & & 111111112 & 0.03 & 0.26 & & \\
\hline & 112222212 & 0.02 & 0.26 & & & & 111112211 & 0.03 & 0.28 & & \\
\hline & 112222222 & 0.02 & 0.28 & & & & 222221111 & 0.03 & 0.31 & & \\
\hline & 221222212 & 0.02 & 0.30 & & & & 211112211 & 0.03 & 0.33 & & \\
\hline Region 5 & 111111211 & 0.09 & 0.09 & 129.6 & 0.0000001 & Region 10 & 211211211 & 0.03 & 0.03 & 54.1 & 0.02 \\
\hline Chr 4p15.1 & 211222122 & 0.08 & 0.16 & & & Chr 7q31.31 & 211121211 & 0.03 & 0.05 & & \\
\hline rs7670648 & 221111211 & 0.07 & 0.24 & & & rs41943 & 122121211 & 0.02 & 0.08 & & \\
\hline$-653.55 \mathrm{~kb}-$ & 121222122 & 0.07 & 0.30 & & & $-3836.29 \mathrm{~kb}-$ & 122211211 & 0.02 & 0.10 & & \\
\hline rs11737583 & 222222122 & 0.07 & 0.37 & & & rs279698 & 222221211 & 0.02 & 0.12 & & \\
\hline & 112111211 & 0.06 & 0.43 & & & & 211222122 & 0.02 & 0.15 & & \\
\hline & 112222122 & 0.06 & 0.50 & & & & 211122122 & 0.02 & 0.17 & & \\
\hline & 122222122 & 0.06 & 0.56 & & & & 222111211 & 0.02 & 0.19 & & \\
\hline & 211111211 & 0.06 & 0.61 & & & & 111111211 & 0.02 & 0.21 & & \\
\hline & 212111211 & 0.05 & 0.67 & & & & 111221211 & 0.02 & 0.24 & & \\
\hline
\end{tabular}


Table 2 (continued)

\begin{tabular}{|c|c|c|c|c|c|c|c|c|c|c|c|}
\hline & Haplotype & $\begin{array}{l}\text { Fre- } \\
\text { quen- } \\
\text { cy }\end{array}$ & $\begin{array}{l}\text { Cumula- } \\
\text { tive fre- } \\
\text { quency }\end{array}$ & $\begin{array}{l}\text { Average } \\
\text { haplotype } \\
\text { disparity } \\
\text { score }\end{array}$ & $\mathrm{p}$ value & & Haplotype & $\begin{array}{l}\text { Fre- } \\
\text { quen- } \\
\text { cy }\end{array}$ & $\begin{array}{l}\text { Cumula- } \\
\text { tive fre- } \\
\text { quency }\end{array}$ & $\begin{array}{l}\text { Average } \\
\text { haplotype } \\
\text { disparity } \\
\text { score }\end{array}$ & $\mathrm{p}$ value \\
\hline $\begin{array}{l}\text { Region } 11 \\
\text { Chr } 8 \text { p } 12 \\
\text { rs } 1487152 \\
-3775.49 \mathrm{~kb}- \\
\text { rs2843910 }\end{array}$ & $\begin{array}{l}212222222 \\
221111222 \\
111111111 \\
112222222 \\
212211111 \\
121111222 \\
222222222 \\
222222111 \\
221122111 \\
112211222\end{array}$ & $\begin{array}{l}0.04 \\
0.04 \\
0.04 \\
0.04 \\
0.04 \\
0.04 \\
0.04 \\
0.04 \\
0.04 \\
0.04\end{array}$ & $\begin{array}{l}0.04 \\
0.09 \\
0.13 \\
0.17 \\
0.21 \\
0.25 \\
0.28 \\
0.32 \\
0.35 \\
0.39\end{array}$ & 70.6 & 0.0001 & $\begin{array}{l}\text { Region } 16 \\
\text { Chr 11p11.2 } \\
\text { rs3824894 } \\
-5446.97 \mathrm{~kb}- \\
\text { rs10751621 }\end{array}$ & $\begin{array}{l}212121211 \\
212112122 \\
122122122 \\
121211211 \\
211212122 \\
121221211 \\
121212122 \\
122112122 \\
211221211 \\
211211211\end{array}$ & $\begin{array}{l}0.06 \\
0.06 \\
0.05 \\
0.05 \\
0.04 \\
0.04 \\
0.04 \\
0.04 \\
0.04 \\
0.04\end{array}$ & $\begin{array}{l}0.06 \\
0.12 \\
0.17 \\
0.22 \\
0.26 \\
0.31 \\
0.35 \\
0.39 \\
0.43 \\
0.47\end{array}$ & 98.0 & 0.0000001 \\
\hline $\begin{array}{l}\text { Region } 12 \\
\text { Chr } 8 q 11.21 \\
\text { (centromeric) } \\
\text { rs2730180 } \\
-12741.94 \mathrm{~kb}- \\
\text { rs3843918 }\end{array}$ & $\begin{array}{l}11111112 \\
222122221 \\
111122221 \\
111222211 \\
111222122 \\
122222221 \\
211222212 \\
222211212 \\
211111222 \\
111211122\end{array}$ & $\begin{array}{l}0.03 \\
0.02 \\
0.02 \\
0.02 \\
0.02 \\
0.02 \\
0.02 \\
0.02 \\
0.02 \\
0.01\end{array}$ & $\begin{array}{l}0.03 \\
0.05 \\
0.07 \\
0.08 \\
0.10 \\
0.12 \\
0.13 \\
0.15 \\
0.16 \\
0.17\end{array}$ & 49.2 & 0.07 & $\begin{array}{l}\text { Region } 17 \\
\text { Chr } 12 \mathrm{q} 12 \\
\text { (centromeric) } \\
\text { rs } 9739928 \\
-5903.63 \mathrm{~kb}- \\
\text { rs } 4293189\end{array}$ & $\begin{array}{l}111111111 \\
222222222 \\
222222221 \\
111111112 \\
111111122 \\
222111111 \\
112222222 \\
111122212 \\
222111112 \\
221122222\end{array}$ & $\begin{array}{l}0.09 \\
0.07 \\
0.07 \\
0.06 \\
0.04 \\
0.04 \\
0.04 \\
0.03 \\
0.03 \\
0.03\end{array}$ & $\begin{array}{l}0.09 \\
0.17 \\
0.24 \\
0.29 \\
0.33 \\
0.37 \\
0.41 \\
0.44 \\
0.47 \\
0.50\end{array}$ & 78.5 & 0.000008 \\
\hline $\begin{array}{l}\text { Region } 13 \\
\text { Chr } 10 \mathrm{p} 12.2 \\
\text { rs7902903 } \\
-1263.80 \mathrm{~kb}- \\
\text { rs11813505 }\end{array}$ & $\begin{array}{l}211121112 \\
122212111 \\
111121221 \\
111112112 \\
111122111 \\
222222121 \\
111121222 \\
222221112 \\
111122222 \\
111111111\end{array}$ & $\begin{array}{l}0.02 \\
0.02 \\
0.02 \\
0.02 \\
0.02 \\
0.02 \\
0.02 \\
0.02 \\
0.02 \\
0.01\end{array}$ & $\begin{array}{l}0.02 \\
0.04 \\
0.07 \\
0.08 \\
0.10 \\
0.12 \\
0.14 \\
0.16 \\
0.17 \\
0.19\end{array}$ & 46.1 & 0.1 & $\begin{array}{l}\text { Region } 18 \\
\text { Chr } 12 \mathrm{q} 21.32 \\
\text { rs7974418 } \\
-5737.84 \mathrm{~kb}- \\
\text { rs11105817 }\end{array}$ & $\begin{array}{l}111111122 \\
111112211 \\
111112222 \\
111111121 \\
222221122 \\
222222211 \\
222221111 \\
111111111 \\
222222221 \\
222221121\end{array}$ & $\begin{array}{l}0.05 \\
0.05 \\
0.05 \\
0.05 \\
0.05 \\
0.05 \\
0.05 \\
0.04 \\
0.04 \\
0.04\end{array}$ & $\begin{array}{l}0.05 \\
0.10 \\
0.15 \\
0.21 \\
0.25 \\
0.30 \\
0.34 \\
0.39 \\
0.43 \\
0.47\end{array}$ & 96.7 & 0.0000001 \\
\hline $\begin{array}{l}\text { Region } 14 \\
\text { Chr 10q22.2 } \\
\text { rs723274 } \\
-3621.06 \mathrm{~kb}- \\
\text { rs2456251 }\end{array}$ & $\begin{array}{l}111212221 \\
111212112 \\
212121111 \\
112121221 \\
222121221 \\
211212112 \\
112121112 \\
121212112 \\
221212111 \\
122121112\end{array}$ & $\begin{array}{l}0.03 \\
0.03 \\
0.03 \\
0.03 \\
0.03 \\
0.03 \\
0.03 \\
0.02 \\
0.02 \\
0.02\end{array}$ & $\begin{array}{l}0.03 \\
0.07 \\
0.10 \\
0.13 \\
0.16 \\
0.18 \\
0.21 \\
0.23 \\
0.25 \\
0.28\end{array}$ & 75.6 & 0.00002 & $\begin{array}{l}\text { Region } 19 \\
\text { Chr } 14 \mathrm{q} 23.3 \\
\text { rs883081 } \\
-2161.95 \mathrm{~kb}- \\
\text { rs11158685 }\end{array}$ & $\begin{array}{l}222211222 \\
222211111 \\
111122111 \\
111121222 \\
111122222 \\
222212111 \\
111122221 \\
111121111 \\
111121112 \\
222212222\end{array}$ & $\begin{array}{l}0.08 \\
0.08 \\
0.07 \\
0.07 \\
0.07 \\
0.07 \\
0.06 \\
0.06 \\
0.06 \\
0.05\end{array}$ & $\begin{array}{l}0.08 \\
0.16 \\
0.24 \\
0.31 \\
0.37 \\
0.44 \\
0.50 \\
0.56 \\
0.62 \\
0.67\end{array}$ & 105.9 & 0.0000001 \\
\hline $\begin{array}{l}\text { Region } 15 \\
\text { Chr 10q24.2 } \\
\text { rs531676 } \\
-2749.70 \mathrm{~kb}- \\
\text { rs2495717 }\end{array}$ & $\begin{array}{l}112221211 \\
121111222 \\
112222122 \\
212112111 \\
221221211 \\
121222111 \\
221112122 \\
212221222 \\
221111211 \\
221222122\end{array}$ & $\begin{array}{l}0.03 \\
0.03 \\
0.03 \\
0.03 \\
0.02 \\
0.02 \\
0.02 \\
0.02 \\
0.02 \\
0.02\end{array}$ & $\begin{array}{l}0.03 \\
0.06 \\
0.09 \\
0.12 \\
0.14 \\
0.16 \\
0.19 \\
0.21 \\
0.23 \\
0.25\end{array}$ & 60.3 & 0.003 & $\begin{array}{l}\text { Region } 20 \\
\text { Chr X11.1 } \\
\text { (centromeric) } \\
\text { rs6638361 } \\
-14297.41 \mathrm{~kb}- \\
\text { rs } 241393\end{array}$ & $\begin{array}{l}111111211 \\
111111222 \\
111222111 \\
222222111 \\
222111211 \\
111222122 \\
22211111 \\
222111222 \\
111111212 \\
111222121\end{array}$ & $\begin{array}{l}0.06 \\
0.06 \\
0.06 \\
0.06 \\
0.05 \\
0.05 \\
0.03 \\
0.03 \\
0.03 \\
0.03\end{array}$ & $\begin{array}{l}0.06 \\
0.12 \\
0.18 \\
0.23 \\
0.29 \\
0.34 \\
0.37 \\
0.40 \\
0.43 \\
0.46\end{array}$ & 86.4 & 0.0000006 \\
\hline
\end{tabular}


Table 3. Average haplotype disparity scores of the most frequent haplotypes in different HapMap populations

\begin{tabular}{|c|c|c|c|c|c|c|c|c|c|c|c|c|}
\hline $\mathrm{ROH}$ & $58 \mathrm{C}$ & ASW & CEU & $\mathrm{CHB}$ & CHD & GIH & JPT & LWK & MEX & MKK & TSI & YRI \\
\hline 1 & $103.3^{c}$ & & $103.4^{\mathrm{c}}$ & $79.9^{c}$ & & & $84.9^{\mathrm{c}}$ & & & & & $67.7^{\mathrm{b}}$ \\
\hline 2 & $109.4^{\mathrm{c}}$ & & & & & & & & & & & \\
\hline 3 & $89.1^{\mathrm{c}}$ & 31.5 & $75.3^{\mathrm{c}}$ & 44 & 49.9 & $53.5^{\mathrm{a}}$ & 37.7 & 29.7 & $65.4^{\mathrm{b}}$ & $51.7^{\mathrm{a}}$ & $76^{c}$ & 29.6 \\
\hline 4 & $83.5^{c}$ & & $69.8^{\mathrm{b}}$ & 13.9 & & & 24.8 & & & & & 21.2 \\
\hline 5 & $129.6^{c}$ & $79.7^{c}$ & $116.8^{c}$ & $88.5^{\mathrm{c}}$ & $94.6^{\mathrm{C}}$ & $116.9^{c}$ & $103^{c}$ & 37.7 & & 47.8 & $125.3^{c}$ & 22 \\
\hline 6 & $71.2^{\mathrm{c}}$ & & & & & & & & & & & \\
\hline 7 & $64.9^{\mathrm{b}}$ & 14.8 & $58.9^{\mathrm{b}}$ & 36.4 & & 40.4 & 27.6 & 9.6 & & & & 10.8 \\
\hline 8 & $121.3^{c}$ & & $109.4^{\mathrm{c}}$ & 45.3 & & & 45.1 & 33.8 & & & & 13.4 \\
\hline 9 & $76^{c}$ & & & & & & & & & & & \\
\hline 10 & $54.1^{\mathrm{a}}$ & & & & & & & & & & & \\
\hline 11 & $70.6^{\mathrm{b}}$ & 31.7 & $72.5^{\mathrm{c}}$ & 26.8 & 26.1 & $61.5^{\mathrm{b}}$ & 16.9 & & & 16.8 & $70.5^{\mathrm{b}}$ & 23.1 \\
\hline 12 & 49.2 & 33.1 & 45.9 & 16.1 & 21.6 & 32 & 34.6 & 7.2 & 42.1 & 12.4 & 48.8 & 6.8 \\
\hline 13 & 46.1 & 13.7 & $53.3^{\mathrm{a}}$ & 5.3 & 22.1 & $57.3^{b}$ & 14.9 & 18.5 & 27.2 & 14.6 & $59.1^{\mathrm{b}}$ & 17.6 \\
\hline 14 & $75.6^{c}$ & 31.9 & $85.1^{\mathrm{c}}$ & 6.9 & 6.4 & 26.7 & 6.2 & & 46.4 & 8.3 & $53.5^{\mathrm{a}}$ & 6.5 \\
\hline 15 & $60.3^{\mathrm{b}}$ & 14.1 & $66^{\mathrm{b}}$ & 10 & 9.7 & 12.4 & 7.4 & & 48.5 & 9.1 & $71.2^{\mathrm{c}}$ & 8.3 \\
\hline 16 & $98^{c}$ & & 44.3 & 27.5 & & & 39.2 & & & & & 10.1 \\
\hline 17 & $78.5^{c}$ & 40 & $67.1^{\mathrm{b}}$ & 27.3 & & & 26.5 & & & 47.7 & & 26.9 \\
\hline 18 & $96.7^{\mathrm{c}}$ & 12.5 & $96.9^{c}$ & $60.5^{b}$ & 37.3 & & 30.1 & 25.2 & 50.1 & & & 11.8 \\
\hline 19 & $105.9^{c}$ & & $90.5^{\mathrm{c}}$ & $87.3^{c}$ & & & 38.6 & & & & $86.1^{c}$ & 20.5 \\
\hline 20 & $86.4^{c}$ & & & & & & & & & & & \\
\hline Average & 84.5 & 31.0 & 76.2 & 37.0 & 31.6 & 48.9 & 36.3 & 21.1 & 46.6 & 25.0 & 72.5 & 18.9 \\
\hline
\end{tabular}

gest that these haplotypes reflect ancient founder haplotypes which were present at a time of very small effective population size and which have subsequently become common through a process of genetic drift, with very little modification from subsequent recombination or mutation.

The second thing to note is that the haplotypes show marked disparity, resulting in several completely yin yang pairs and others which differ from each other at several SNPs simultaneously. This is not what one would expect to result from a process of sequential mutation and recombination. Even if we were witnessing ancestral founder haplotypes which had become common through genetic drift, it would not be expected that these ancestral haplotypes would show exceptional disparity from each other.

We emphasise that we do not see how this could be a chance phenomenon. The previous investigation of yin yang haplotypes concluded that they could arise by a neutral evolutionary model incorporating mutation and recombination [1]. However, the definition that was used to determine whether a region met the criteria for containing yin yang haplotypes was very different from ours and perhaps somewhat undemanding. To qualify, one had to be able to find one yin yang pair among all common haplotypes of 5 SNPs or more. To understand how likely or not this might be to occur by chance is somewhat analogous to the problem of calculating the probability of there being two people in the room who share a birthday. If there are quite a number of common 5-SNP haplotypes then it may not be too difficult to find one pair which shows disparity at all 5 SNPs. Our study differs from the previous one in two ways. Firstly, we have only studied areas where $\mathrm{ROHs}$ are common. In most of the genome, recombination is frequent and there would be no possibility for long yin yang haplotypes to survive, even if they had originally been present. However, areas which have retained $\mathrm{ROHs}$ extending over long distances must have low rates of recombination and hence offer an opportunity to study haplotypes which have been retained largely intact. Secondly, we have studied all pairs among the high-frequency haplotypes rather than trawling through all possible pairs to find a single pair which is completely yin yang. What we discovered are haplotype sets which do contain completely yin yang pairs but which also demonstrate far higher overall disparity than could be ex- 
Table 4. An example scenario showing how yin yang haplotypes can arise when selecting SNPs with high MAFs from a mixture of two populations

\begin{tabular}{rllllll}
\hline SNP & $\begin{array}{l}\text { Popula- } \\
\text { tion 1 }\end{array}$ & $\begin{array}{l}\text { Popula- } \\
\text { tion 2 }\end{array}$ & $\begin{array}{l}\text { Mix of } \\
\text { popula- } \\
\text { tions 1 and 2 }\end{array}$ & $\begin{array}{l}\text { SNPs with high } \\
\text { MAF in mixed } \\
\text { population }\end{array}$ & $\begin{array}{l}\text { Haplotypes } \\
\text { of SNPs with } \\
\text { high MAF }\end{array}$ \\
\hline 1 & $\mathrm{AB}$ & $\mathrm{AB}$ & $\mathrm{AB}$ & $\checkmark$ & $\mathrm{A}$ & $\mathrm{B}$ \\
2 & $\mathrm{AB}$ & $\mathrm{AB}$ & $\mathrm{AB}$ & & & \\
3 & $\mathrm{AB}$ & $\mathrm{AB}$ & $\mathrm{AB}$ & $\checkmark$ & $\mathrm{B}$ & $\mathrm{A}$ \\
4 & $\mathrm{AB}$ & $\mathrm{AB}$ & $\mathrm{AB}$ & $\checkmark$ & $\mathrm{B}$ & $\mathrm{A}$ \\
5 & $\mathrm{AB}$ & $\mathrm{AB}$ & $\mathrm{AB}$ & & & \\
6 & $\mathrm{AB}$ & $\mathrm{AB}$ & $\mathrm{AB}$ & $\checkmark$ & $\mathrm{B}$ & $\mathrm{A}$ \\
7 & $\mathrm{AB}$ & $\mathrm{AB}$ & $\mathrm{AB}$ & $\checkmark$ & $\mathrm{A}$ & $\mathrm{B}$ \\
8 & $\mathrm{AB}$ & $\mathrm{AB}$ & $\mathrm{AB}$ & $\checkmark$ & $\mathrm{A}$ & $\mathrm{B}$ \\
9 & $\mathrm{AB}$ & $\mathrm{AB}$ & $\mathrm{AB}$ & & & \\
10 & $\mathrm{AB}$ & $\mathrm{AB}$ & $\mathrm{AB}$ & & & \\
11 & $\mathrm{AB}$ & $\mathrm{AB}$ & $\mathrm{AB}$ & $\checkmark$ & $\mathrm{B}$ & $\mathrm{A}$ \\
12 & $\mathrm{AB}$ & $\mathrm{AB}$ & $\mathrm{AB}$ & $\checkmark$ & $\mathrm{B}$ & $\mathrm{A}$ \\
13 & $\mathrm{AB}$ & $\mathrm{AB}$ & $\mathrm{AB}$ & & & \\
14 & $\mathrm{AB}$ & $\mathrm{AB}$ & $\mathrm{AB}$ & $\checkmark$ & $\mathrm{A}$ & $\mathrm{B}$ \\
15 & $\mathrm{AB}$ & $\mathrm{AB}$ & $\mathrm{AB}$ & & & \\
\hline
\end{tabular}

The alleles are represented by A and B, with rare alleles shown in a smaller font. Genotypes and haplotypes across the SNPs are displayed in vertical columns.

Table 5. Example mechanism whereby a new pair of yin yang haplotypes could be created from the original pair

\begin{tabular}{lllll}
\hline SNP & Parent 1 & Parent 1 & Child 1 & Child 2 \\
\hline 1 & A & B & A & B \\
3 & B & A & B & A \\
4 & B & A & B & A \\
6 & B & A & B & A \\
7 & A & B & A & B \\
8 & A & B & A & B \\
11 & B & A & A & B \\
12 & B & A & A & B \\
14 & A & B & B & A \\
\hline
\end{tabular}

In each case, the original haplotypes recombine between SNPs 8 and 11 to form a new child haplotype, but with different portions from each parent haplotype being retained.

pected if haplotypes were generated at random. Some results are highly statistically significant. Such haplotype sets cannot possibly be produced by a neutral evolutionary model, which by its nature produces haplotypes which are more similar to each other than those randomly generated.
We do not understand what mechanism might have produced the highly disparate haplotypes which we observe. Theoretically, a pair of yin yang haplotypes could occur from one of the following mechanisms: a number of mutations all occur simultaneously; a population is founded by two subjects coming from populations which have evolved separately over a protracted period; there are selection pressures which give survival advantages to one or other set of alleles but not to haplotypes bearing a mixture. None of these explanations seems plausible. We believe that a partial explanation might involve a combination of founder effects and ascertainment. We have sought to illustrate this process in table 4 . We deliberately chose to study SNPs with a high MAF. We propose that we begin with an admixture between two founder populations, each of small effective size, and that there are a number of polymorphic SNPs present in these populations. Each SNP will have a common allele and a rarer one. If the common allele is the same in both founder populations then in the combined population this SNP will have low MAF. If, however, the common allele differs between the founder populations then in the combined population both alleles may end up with a fairly high frequency. If subsequently, as we have done, we select SNPs with high MAF we may in fact be selecting the SNPs in which the commoner allele was different in the two founder populations. Haplotypes formed from these SNPs would then tend to be made up of alleles from one or other founder population and hence would demonstrate the yin yang effect. 'Pure' yin yang haplotypes might reflect the alleles from each founder population, whereas a limited number of recombination and mutation events might produce modified haplotypes which nevertheless displayed high levels of disparity. One can even speculate on a mechanism for producing additional yin yang pairs from the original pair and this is illustrated in table 5. If there is a particular location where recombination does occur with relatively high frequency then two recombination events at this location, each occurring between the original yin yang haplotypes, could produce two new child haplotypes which would have different alleles at every SNP, thus producing a different yin yang pair.

When we went on to study different HapMap samples we observed that excess haplotype disparity occurred in some cohorts but not in others. In fact, the highly significant results seem to be concentrated in the cohorts of European origin, CEU and TSI. This may reflect some peculiarity of the history of European population, for example involving migrations and conquests. Alternatively,

Hum Hered 2010;69:184-192 
it may be that the effect is confined to European subjects because we selected SNPs with high MAF in the original European sample, and it may be that if we had selected SNPs with high MAF in a different population then that cohort would also have shown excess haplotype disparity.

We studied only locations where ROHs are common and, as we have already said, we could not expect long haplotypes to survive intact in parts of the genome where recombination occurred more commonly. However, it may still be the case that small numbers of diverse haplotypes were originally present. If this were the case then methods of modelling haplotype history which sought to use recombination and mutation events to converge to a single original haplotype might not accurately model the true state of affairs.

To conclude, we have discovered that locations where $\mathrm{ROH}$ are common harbour surprisingly long common haplotypes and that these show surprising diversity, supporting the existence of a yin yang effect. We are uncertain as to the causes of this but we do think that these haplotypes must reflect ancient founder effects within the population studied and hence that they could be potentially valuable for elucidating features of the history of the population. We look forward to this phenomenon being investigated further, in European and other populations.

\section{References}

1 Zhang J, Rowe WL, Clark AG, Buetow KH: Genomewide distribution of high-frequency, completely mismatching SNP haplotype pairs observed to be common across human populations. Am J Hum Genet 2003;73: 1073-1081.

-2 Curtis D, Vine AE, Knight J: Study of regions of extended homozygosity provides a powerful method to explore haplotype structure of human populations. Ann Hum Genet 2008; 72:261-278.

>3 Gibson J, Morton NE, Collins A: Extended tracts of homozygosity in outbred human populations. Hum Mol Genet 2006;15:789795.
4 Simon-Sanchez J, Scholz S, Fung HC, Matarin M, Hernandez D, Gibbs JR, Britton A, de Vrieze FW, Peckham E, Gwinn-Hardy K, Crawley A, Keen JC, Nash J, Borgaonkar D, Hardy J, Singleton A: Genome-wide SNP assay reveals structural genomic variation, extended homozygosity and cell-line induced alterations in normal individuals. Hum Mol Genet 2007;16:1-14.

5 Broman KW, Weber JL: Long homozygous chromosomal segments in reference families from the centre d'Etude du polymorphisme humain. Am J Hum Genet 1999;65:14931500.

6 Curtis D: Extended homozygosity is not usually due to cytogenetic abnormality. BMC Genet 2007;8:67.

7 Lencz T, Lambert C, DeRosse P, Burdick KE, Morgan TV, Kane JM, Kucherlapati R, Malhotra AK: Runs of homozygosity reveal highly penetrant recessive loci in schizophrenia. Proc Natl Acad Sci USA 2007;104: 19942-19947.

$\checkmark 8$ Vine AE, McQuillin A, Bass NJ, Pereira A, Kandaswamy R, Robinson M, Lawrence J, Anjorin A, Sklar P, Gurling HM, Curtis D: No evidence for excess runs of homozygosity in bipolar disorder. Psychiatr Genet 2009;19: 165-170.
>9 WTCCC: Genome-wide association study of 14,000 cases of seven common diseases and 3,000 shared controls. Nature 2007;447:661678.

10 Zhao JH, Lissarrague S, Essioux L, Sham PC: Genecounting: Haplotype analysis with missing genotypes. Bioinformatics 2002;18: 1694-1695.

11 North BV, Curtis D, Sham PC: A note on calculation of empirical $\mathrm{p}$ values from monte carlo procedure. Am J Hum Genet 2003;72: 498-499.

12 Curtis D, Knight J, Sham PC: Program report: Genecounting support programs. Ann Hum Genet 2006;70:277-279.

13 The International HapMap Consortium: The International HapMap project. Nature 2003;426:789-796. 